\title{
Menopausal Symptoms in Japanese Nurses: Differences between Smokers and Non-Smokers
}

\author{
Yukie Matsuura ${ }^{*}$, Kazuyo Matsuzaki ${ }^{2}$, Toshiyuki Yasui ${ }^{1}$ \\ ${ }^{1}$ Department of Reproductive and Menopausal Medicine, Graduate School of Biomedical Sciences, Tokushima University, \\ Tokushima, Japan \\ ${ }^{2}$ Nursing Department, Tokushima Red Cross Hospital, Tokushima, Japan \\ Email: *y.matsuura@tokushima-u.ac.jp
}

How to cite this paper: Matsuura, Y., Matsuzaki, K. and Yasui, T. (2020) Menopausal Symptoms in Japanese Nurses: Differences between Smokers and Non-Smokers. Health, 12, 474-485.

https://doi.org/10.4236/health.2020.125037

Received: April 19, 2020

Accepted: May 16, 2020

Published: May 19, 2020

Copyright (C) 2020 by author(s) and Scientific Research Publishing Inc. This work is licensed under the Creative Commons Attribution International License (CC BY 4.0).

http://creativecommons.org/licenses/by/4.0/

\begin{abstract}
This study was conducted using a self-administered questionnaire to clarify the differences in menopausal symptoms between smokers and non-smokers in Japanese nurses and the relationship between job-related stress and smoking. The proportion of smokers was $10.3 \%$. Smokers are more likely than non-smokers to have menopausal symptoms such as heart beating quickly or strongly, difficulty in sleeping, loss of interested in most things and night sweat. The scores for anxiety and vasomotor factors in smokers were significantly higher than non-smokers in the postmenopausal stage. Support to stop smoking should be provided before menopausal transition.
\end{abstract}

\section{Keywords}

Smoking, Menopausal Symptoms, Nurses

\section{Introduction}

Menopausal symptoms are variety of symptoms that occur during menopause and are not caused by organic changes, caused mainly by decrease in ovarian function, manifested by the combined effects of physical changes by aging, mental and psychological factors, and sociocultural environmental factors [1], which are attributed to hormonal changes, differ depending on the type of occupations, life events and personality. In addition, it is known that the prevalence of hot flashes is higher in Caucasians than in Asian women [2]. It has been reported that the frequencies of menopausal symptoms such as fatigue, irritability and arthralgia were high in nurses compared with those in a community 
population [3]. We also reported that nurses were likely to have a feeling of being tired or lacking in energy, irritability, difficulty in concentration, feeling tense or nervous, and feeling unhappy or depressed as menopausal symptoms [4]. High levels of job-related stress were significantly associated with high scores on Greene's climacteric scale, particularly for psychological symptoms [4].

On the other hand, menopausal symptoms have been shown to be affected by lifestyle [5]. Smoking is an important factor that affects menopausal symptoms. Many previous studies revealed that smoking status was associated with intensity of hot flashes in middle-aged women [5] [6] [7]. It has also been reported that smoking was one of the factors contributing to more severe menopausal symptoms [8] and that smoking was one of factors related to a higher prevalence of moderate to severe menopausal symptoms [9]. Gold et al. [5] reported that smoking was associated with menopausal symptoms such as night sweats, heart pounding, and difficult sleeping. In Japanese women, smoking status was shown to be significantly related to menopausal symptoms such as hot flashes, experiencing poor memory, muscle and joint pain, difficult in sleeping, headache, general fatigue and drying skin [10]. However, there have been few studies on the associations between menopausal symptoms and smoking in nurses.

There have been some studies on smoking and menopause, with focus on the onset of menopause in nurses. It has been reported that the prevalence of past and current smoking was significantly lower in postmenopausal nurses than in premenopausal nurses [11]. Current smoking and the number of cigarettes smoked per day before menopause were significantly related to onset of menopause [12]. The median age at menopause in women who smoked was significantly younger than that in women who did not smoke in Japanese nurses [13]. Since smoking was shown to be related to younger age at menopause, smoking may also be associated with occurrence of estrogen deficiency induced diseases in nurses.

The aim of the present study is to clarify the differences in menopausal symptoms between smokers and non-smokers in Japanese nurses and the relationship between job-related stress as a characteristic of nurse and smoking.

\section{Materials and Methods}

\subsection{Subjects}

This study was cross sectional survey, which was conducted from September to December in 2013. We first asked national, public and private hospitals in Japan whether they could assist with our research. 26 national and public hospitals and two private hospitals agreed to cooperate. A total of 1700 female registered nurses aged 45 - 60 years who were working in hospitals. The hospitals provided the invitation letters that was included the purposes and procedure of the study to the participants. It was stated in this letter that cooperation in the questionnaire survey is based on free will and that there is no disadvantage for subjects 
who do not cooperate. Agreement for participation in this study was obtained by having the questionnaire form returned to us by mail.

\subsection{Questionnaire}

The self-administered questionnaire consisted of three parts. The first part of the questionnaire consisted of questions on socio-demographic factors, life style and medical history including questions on age, height and weight for calculating body mass index (BMI), marital status, menstrual and menopausal status, drug treatment, current smoking habit, and alcohol drinking habit. Menstrual and menopausal status was divided into premenopause (regular menstrual cycle during the past 12 months), perimenopause (irregular menstruation during the past 12 months) and postmenopause (no menstruation during the past 12 months).

The second part of the questionnaire consisted of questions on menopausal symptoms assessed by Greene's climacteric scale [14], a standardized scale that measures the extent to which an individual is affected by menopausal symptoms. The scale includes four symptom clusters: psychological, somatic and vasomotor symptoms, and loss of sexual interest is also assessed. Each symptom is rated by the woman herself according to its severity using a four-point rating scale: not at all (0), a little (1), quite a bit (2), and extremely (3). Symptoms 1 - 11 address psychological symptoms divided into a measure of anxiety and a measure of depression. Somatic aspects are addressed in symptoms $12-18$ and vasomotor symptoms are addressed in symptoms $19-20$. Symptom 21 is a probe for sexual dysfunction. The total Greene Climacteric score is the sum of all 21 scores.

The third part of the questionnaire consisted of questions on occupational characteristics including job rank, years of nursing experience and frequency of night shift. Job-related stress factors were assessed by the questionnaire in the Brief Job Stress Questionnaire, which was provided by the Ministry of Labour in Japan [15]. There were 17 questions in 9 categories, which were quantitative overload (Q1-3), qualitative overload (Q4-6), physical overload (Q7), job control (Q8-10), skill discretion (Q11), interpersonal relationships (Q12-14), workplace environment (Q15), job fitness (Q16) and satisfaction with work (Q17). A response of "Yes (1)", "Yes to some extent (2)", "Not really (3)" or "No (4)" was given to the following 17 statements: 1) You have to do an enormous amount of work, 2) You cannot complete all of your work in the allotted time, 3) You have to work very hard, 4) You have to focus your attention quite a lot, 5) You do a difficult job that requires a high level of knowledge and skill, 6) You have to constantly think about work during your working hours, 7) You do a lot of physical work, 8) You can work at your own pace, 9) You can decide the order in which you do your work and the way you do it, 10) You can express your own opinions on the workplace strategy, 11) You do not frequently use your skills and knowledge in the job, 12) There are differences of opinion within your department, 13) Your department does not get on well with other departments, 14) 
The atmosphere in your workplace is friendly, 15) The environment of your workplace (noise, light, humidity and ventilation)is not so good, 16) The content of your work suits you, and 17) You have job satisfaction in your work. The items, which were 8), 9), 10), 14), 16) and 17), were scored in reverse, such that lower scores consistently indicated higher degrees of job-related stress.

This study was approved by Ethics Committee of Tokushima University Hospital (number 1772).

\subsection{Statistical Analysis}

Baseline characteristics of the participants such as age and BMI are presented as means and standard deviation. Each categorized variable is expressed as number with percentage.

We analyzed by using the Mann-Whitney $\mathrm{U}$ test for differences in age, BMI, age in each menopausal transition stage and age at onset of menopausal symptoms between the two groups (smokers and non-smokers). The significance of differences in the proportion of menopausal symptoms was evaluated by the chi-square test. Differences in the proportions of low score and high score groups between current smokers and non-smokers were evaluated by the chi-square test. The Mann-Whitney $U$ test was used to determine the differences in menopausal symptoms between current smokers and non-smokers among total, pre-, peri- and postmenopausal women. All $\mathrm{p}$ values are two-tailed and those less than 0.05 were considered to be statistically significant. Statistical analyses for data evaluation were carried out using SPSS version 21 for Windows.

\section{Results}

The overall response rate was $77.4 \%$ (1316/1700). Incomplete questionnaires (n $=16)$ and nurses who did not meet the inclusion criterion of age $(n=16)$ were excluded. In addition, nurses who had diagnosed and taken any medications for gynecological malignancies $(n=13)$, mental disorders $(n=13)$, thyroid diseases $(n=50)$, coronary heart diseases $(n=14)$ and rheumatoid arthritis $(n=15)$ were excluded. Thus, questionnaires from 1179 nurses were used for analysis, 10.3\% $(122 / 1179)$ were smokers and $89.7 \%$ (1057/1179) were non-smokers.

\subsection{Background Characteristics of the Participants}

As shown in Table 1, there was a significant difference in the proportion of nurses in menopausal status between smokers and non-smokers $(\mathrm{p}=0.029)$. The proportion of smokers in each menopausal status was $6.7 \%(23 / 341)$ in premenopause, $10.8 \%(24 / 223)$ in perimenopause and $12.2 \%$ (75/615) in postmenopause. The age in each menopausal status was not significantly different between smokers and non-smokers. The proportion of nurses who had experiences of menopausal symptoms and the age when symptoms started were not significantly different between smokers and non-smokers. The proportion of nurses who had an alcohol drinking habit was higher in smokers than in non-smokers 
Table 1. Baseline characteristics of smokers and non-smokers.

\begin{tabular}{|c|c|c|c|c|c|c|}
\hline \multirow{2}{*}{ Age (years) ${ }^{\mathrm{a}^{*}}$} & & \multicolumn{2}{|c|}{$\begin{array}{l}\text { Smokers } \\
(\mathrm{n}=122)\end{array}$} & \multicolumn{2}{|c|}{$\begin{array}{c}\text { Non-smokers } \\
(\mathrm{n}=1057)\end{array}$} & \multirow{2}{*}{$\begin{array}{c}\mathrm{p} \text { value } \\
0.143\end{array}$} \\
\hline & & 51.7 & $(3.9)$ & 51.2 & $(4.2)$ & \\
\hline Body mass index $\left(\mathrm{kg} / \mathrm{m}^{2}\right)^{\mathrm{a}^{*}}$ & & 22.3 & $(3.5)$ & 22.4 & $(3.1)$ & 0.350 \\
\hline \multirow[t]{3}{*}{ Menstrual status (No, \%) } & Pre-menopause & 23 & $(18.9)$ & 318 & $(30.1)$ & \multirow{3}{*}{0.029} \\
\hline & Peri-menopause & 24 & $(19.7)$ & 199 & $(18.8)$ & \\
\hline & Post-menopause & 75 & $(61.5)$ & 540 & $(51.1)$ & \\
\hline \multirow[t]{2}{*}{ Have experiences of menopausal symptoms } & Yes & 73 & $(59.8)$ & 565 & (53.5) & \multirow{2}{*}{0.212} \\
\hline & No & 49 & $(40.2)$ & 492 & $(46.5)$ & \\
\hline \multicolumn{2}{|c|}{ Age when menopausal symptoms started (years) $)^{\mathrm{a}^{*}}$} & 46.9 & $(4.8)$ & 47.9 & $(3.8)$ & \multirow[t]{2}{*}{0.231} \\
\hline \multirow[t]{3}{*}{ Working night shift (No, \%) } & Yes & 93 & $(76.2)$ & 777 & $(73.5)$ & \\
\hline & No & 29 & $(23.8)$ & 278 & $(26.3)$ & \multirow[t]{2}{*}{0.587} \\
\hline & Unknown & 0 & $(0.0)$ & 2 & $(0.2)$ & \\
\hline \multirow[t]{4}{*}{ Marital status (No, \%) } & Married & 74 & $(60.7)$ & 772 & $(73.0)$ & \multirow{4}{*}{0.039} \\
\hline & Single & 27 & $(22.1)$ & 156 & $(14.7)$ & \\
\hline & Divorce & 14 & $(11.5)$ & 88 & $(8.3)$ & \\
\hline & Others & 7 & (5.7) & 41 & $(4.0)$ & \\
\hline \multirow[t]{2}{*}{ Alcohol drinking habit (No, \%) } & Yes & 51 & $(41.8)$ & 310 & $(29.3)$ & \multirow{2}{*}{0.007} \\
\hline & No & 71 & $(58.2)$ & 747 & $(70.7)$ & \\
\hline
\end{tabular}

a: Mean (SD). The values in parenthesis excluding age and body mass index are percentages. Chi square test, *Mann-Whitney U test.

$(\mathrm{p}=0.007)$. With regard to current healthcare activities, the proportions of current smokers who had sufficient sleep and rest, paid attention to food and nutrition, had a medical checkup regularly, and did exercise and sports were significantly lower than those of non-smokers $(\mathrm{p}=0.038, \mathrm{p}=0.026, \mathrm{p}<0.001$ and $\mathrm{p}=$ 0.027 , respectively) (data not shown).

\subsection{Menopausal Symptoms in Smokers and Non-Smokers}

We divided the nurses into a group with a low score for symptoms (not at all or a little) and a group with a high score for symptoms (quite a bit or extremely). The proportions of smokers were significantly higher than the proportions of non-smokers who had symptoms of "heart beating quickly or strongly" ( $\mathrm{p}=$ $0.039)$, "difficulty in sleeping" ( $p<0.001)$, "loss of interest in most things" $(p=$ $0.012)$ and "sweating at night" ( $\mathrm{p}=0.020)$ (Table 2$)$.

\subsection{Menopausal Symptoms by Clusters in Smokers and Non-Smokers in Pre-, Peri- and Postmenopausal Stages}

The scores for total menopausal symptoms and for clusters of menopausal symptoms (psychological, somatic, vasomotor and sexual factors) and the 
Table 2. Menopausal symptoms in smokers and non-smokers.

\begin{tabular}{|c|c|c|c|c|c|c|c|c|c|}
\hline \multirow[b]{3}{*}{ 1. Heart beating quickly or strongly } & \multicolumn{4}{|c|}{ Smokers $(\mathrm{n}=122)$} & \multicolumn{4}{|c|}{ Non-smokers $(n=1057)$} & \multirow{3}{*}{$\begin{array}{c}\mathrm{X}^{2} \mathrm{p} \text { value } \\
0.039\end{array}$} \\
\hline & \multicolumn{2}{|c|}{ Low score group } & \multicolumn{2}{|c|}{ High score group } & \multicolumn{2}{|c|}{ Low score group } & \multicolumn{2}{|c|}{ High score group } & \\
\hline & 113 & $(92.6)$ & 9 & $(7.4)$ & 1022 & $(96.7)$ & 35 & $(3.3)$ & \\
\hline 2. Feeling tense or nervous & 99 & $(81.1)$ & 23 & $(18.9)$ & 908 & $(85.9)$ & 149 & $(14.1)$ & 0.175 \\
\hline 3. Difficulty in sleeping & 95 & $(77.9)$ & 27 & $(22.1)$ & 947 & $(89.6)$ & 110 & $(10.4)$ & $<0.001$ \\
\hline 4. Excitable & 114 & $(93.4)$ & 8 & $(6.6)$ & 992 & $(93.9)$ & 65 & $(6.1)$ & 0.843 \\
\hline 5. Attacks of pain & 117 & $(95.9)$ & 5 & $(4.1)$ & 1035 & $(97.9)$ & 22 & $(2.1)$ & 0.189 \\
\hline 6. Difficulty in concentrating & 100 & $(82.0)$ & 22 & $(18.0)$ & 922 & $(87.2)$ & 135 & $(12.8)$ & 0.121 \\
\hline 7. Feeling tired or lacking in energy & 73 & $(59.8)$ & 49 & $(40.2)$ & 549 & $(51.9)$ & 508 & $(48.1)$ & 0.104 \\
\hline 8. Loss of interest in most things & 93 & $(76.2)$ & 29 & $(23.8)$ & 901 & $(85.2)$ & 156 & $(14.8)$ & 0.012 \\
\hline 9. Feeling unhappy or depressed & 98 & $(80.3)$ & 24 & $(19.7)$ & 904 & $(85.5)$ & 153 & $(14.5)$ & 0.140 \\
\hline 10. Crying spells & 120 & $(98.4)$ & 2 & $(1.6)$ & 1013 & $(95.8)$ & 44 & $(4.2)$ & 0.221 \\
\hline 11. Irritability & 98 & $(80.3)$ & 24 & $(19.7)$ & 851 & $(80.5)$ & 206 & $(19.5)$ & 1.000 \\
\hline 12. Feeling dizzy or faint & 114 & $(93.4)$ & 8 & $(6.6)$ & 995 & $(94.1)$ & 62 & $(5.9)$ & 0.688 \\
\hline 13. Pressure or tightness in head or body & 120 & $(98.4)$ & 2 & $(1.6)$ & 1032 & $(97.6)$ & 25 & $(2.4)$ & 1.000 \\
\hline 14. Parts of body feel numb or tingling & 118 & $(96.7)$ & 4 & (3.3) & 1020 & $(96.5)$ & 37 & $(3.5)$ & 1.000 \\
\hline 15. Headaches & 107 & $(87.7)$ & 15 & $(12.3)$ & 911 & $(86.2)$ & 146 & $(13.8)$ & 0.780 \\
\hline 16. Muscle and joint pains & 102 & $(83.6)$ & 20 & $(16.4)$ & 888 & $(84.0)$ & 169 & $(16.0)$ & 0.897 \\
\hline 17. Loss of feeling in hands or feet & 120 & $(98.4)$ & 2 & $(1.6)$ & 1030 & $(97.4)$ & 27 & $(2.6)$ & 0.761 \\
\hline 18. Breathing difficulties & 120 & $(98.4)$ & 2 & $(1.1)$ & 1046 & $(99.0)$ & 11 & $(1.0)$ & 0.636 \\
\hline 19. Hot flashes & 105 & $(86.1)$ & 17 & $(13.9)$ & 944 & $(89.3)$ & 113 & $(10.7)$ & 0.285 \\
\hline 20. Sweating at night & 107 & $(87.7)$ & 15 & $(12.3)$ & 992 & $(93.9)$ & 65 & $(6.1)$ & 0.020 \\
\hline 21. Loss of interest in sex & 74 & $(60.7)$ & 48 & $(39.3)$ & 595 & $(56.3)$ & 462 & $(43.7)$ & 0.386 \\
\hline
\end{tabular}

Number (\%); High score group: quite a bit or extremely, Low score group: not at all or a little.

depression subcluster were not significantly different between smokers and non-smokers. The score for the anxiety subcluster was significantly higher in smokers than in non-smokers ( $p=0.047)$. In postmenopausal women, the scores for total menopausal symptoms $(\mathrm{p}=0.033)$ and for clusters of anxiety factors $(\mathrm{p}$ $=0.035)$ and vasomotor factors $(\mathrm{p}=0.002)$ were significantly higher in smokers than in non-smokers (Table 3).

\subsection{Job-Related Stress Factors in Smokers and Non-Smokers in Pre-, Peri- and Postmenopausal Stages}

There were no significant differences in job-related stress factors between smokers and non-smokers (Table 4). With regard to job-related stress factors between smokers and non-smokers according to menstrual status, there was no differences in job-relates stress factors between smokers and non-smokers in both premenopausal and postmenopausal stages. In perimenopause, only the 
Table 3. Menopausal symptoms by clusters in smokers and non-smokers in pre-, peri- and post-menopause.

\begin{tabular}{|c|c|c|c|c|c|c|c|c|c|c|c|c|}
\hline & \multicolumn{3}{|c|}{ Total } & \multicolumn{3}{|c|}{ Premenopause } & \multicolumn{3}{|c|}{ Perimenopause } & \multicolumn{3}{|c|}{ Postmenopause } \\
\hline & $\begin{array}{l}\text { Smokers } \\
(\mathrm{n}=122)\end{array}$ & $\begin{array}{c}\text { non- } \\
\text { smokers } \\
(\mathrm{n}=1057)\end{array}$ & $\mathrm{p}$ value & $\begin{array}{l}\text { Smokers } \\
(\mathrm{n}=23)\end{array}$ & $\begin{array}{c}\text { non- } \\
\text { smokers } \\
(\mathrm{n}=318)\end{array}$ & $\begin{array}{c}\mathrm{p} \\
\text { value }\end{array}$ & $\begin{array}{l}\text { Smokers } \\
(\mathrm{n}=24)\end{array}$ & $\begin{array}{c}\text { non- } \\
\text { smokers } \\
(\mathrm{n}=199)\end{array}$ & $\begin{array}{c}\mathrm{p} \\
\text { value }\end{array}$ & $\begin{array}{l}\text { Smokers } \\
(\mathrm{n}=75)\end{array}$ & $\begin{array}{c}\text { non- } \\
\text { smokers } \\
(\mathrm{n}=540)\end{array}$ & $\begin{array}{c}\mathrm{p} \\
\text { value }\end{array}$ \\
\hline Psychological & $\begin{array}{c}8 \\
(6.0,12.25)\end{array}$ & $\begin{array}{c}8 \\
(5.0,11.0)\end{array}$ & 0.470 & $\begin{array}{c}7 \\
(3.0,10.0)\end{array}$ & $\begin{array}{c}7 \\
(4.0,11.0)\end{array}$ & 0.131 & $\begin{array}{c}8 \\
(5.25,13.0)\end{array}$ & $\begin{array}{c}9 \\
(6.0,12.0)\end{array}$ & 0.972 & $\begin{array}{c}9 \\
(7.0,13.0)\end{array}$ & $\begin{array}{c}8 \\
(5.0,11.0)\end{array}$ & 0.056 \\
\hline Anxiety & $\begin{array}{c}4 \\
(2.0,6.0)\end{array}$ & $\begin{array}{c}3 \\
(2.0,5.0)\end{array}$ & 0.047 & $\begin{array}{c}3 \\
(1.0,5.0)\end{array}$ & $\begin{array}{c}3 \\
(1.0,5.0)\end{array}$ & 0.938 & $\begin{array}{c}3 \\
(2.0,5.75)\end{array}$ & $\begin{array}{c}4 \\
(2.0,5.0)\end{array}$ & 0.838 & $\begin{array}{c}5 \\
(3.0,7.0)\end{array}$ & $\begin{array}{c}4 \\
(2.0,6.0)\end{array}$ & 0.035 \\
\hline Depression & $\begin{array}{c}5 \\
(3.0,6.0)\end{array}$ & $\begin{array}{c}4 \\
(3.0,6.0)\end{array}$ & 0.369 & $\begin{array}{c}3 \\
(2.0,5.0)\end{array}$ & $\begin{array}{c}4 \\
(3.0,6.0)\end{array}$ & 0.333 & $\begin{array}{c}5 \\
(4.0,7.0)\end{array}$ & $\begin{array}{c}5 \\
(3.0,7.0)\end{array}$ & 0.581 & $\begin{array}{c}5 \\
(4.0,6.0)\end{array}$ & $\begin{array}{c}4 \\
(3.0,6.0)\end{array}$ & 0.229 \\
\hline Somatic & $\begin{array}{c}3 \\
(1.0,4.0)\end{array}$ & $\begin{array}{c}2 \\
(1.0,4.0)\end{array}$ & 0.522 & $\begin{array}{c}2 \\
(1.0,3.0)\end{array}$ & $\begin{array}{c}2 \\
(1.0,4.0)\end{array}$ & 0.973 & $\begin{array}{c}2 \\
(1.0,3.75)\end{array}$ & $\begin{array}{c}3 \\
(1.0,5.0)\end{array}$ & 0.319 & $\begin{array}{c}3 \\
(1.0,4.0)\end{array}$ & $\begin{array}{c}2 \\
(1.0,4.0)\end{array}$ & 0.181 \\
\hline Vasomotor & $\begin{array}{c}1 \\
(0.0,2.0)\end{array}$ & $\begin{array}{c}1 \\
(0.0,2.0)\end{array}$ & 0.075 & $\begin{array}{c}0 \\
(0.0,0.0)\end{array}$ & $\begin{array}{c}0 \\
(0.0,1.0)\end{array}$ & 0.227 & $\begin{array}{c}1 \\
(0.0,1.0)\end{array}$ & $\begin{array}{c}1 \\
(0.0,2.0)\end{array}$ & 0.085 & $\begin{array}{c}2 \\
(0.0,2.0)\end{array}$ & $\begin{array}{c}1 \\
(0.0,2.0)\end{array}$ & 0.002 \\
\hline Sexuality & $\begin{array}{c}1 \\
(1.0,2.0)\end{array}$ & $\begin{array}{c}1 \\
(1.0,2.0)\end{array}$ & 0.409 & $\begin{array}{c}2 \\
(1.0,2.0)\end{array}$ & $\begin{array}{c}2 \\
(1.0,2.0)\end{array}$ & 0.966 & $\begin{array}{c}1 \\
(1.0,2.0)\end{array}$ & $\begin{array}{c}2 \\
(1.0,2.0)\end{array}$ & 0.740 & $\begin{array}{c}1 \\
(1.0,2.0)\end{array}$ & $\begin{array}{c}1 \\
(1.0,2.0)\end{array}$ & 0.913 \\
\hline Total score & $\begin{array}{c}13 \\
(10.0,19.0)\end{array}$ & $\begin{array}{c}13 \\
(8.0,18.0)\end{array}$ & 0.404 & $\begin{array}{c}11 \\
(6.0,14.0)\end{array}$ & $\begin{array}{c}11 \\
(7.0,16.25)\end{array}$ & 0.321 & $\begin{array}{c}12 \\
(8.5,17.75)\end{array}$ & $\begin{array}{c}14 \\
(9.0,20.0)\end{array}$ & 0.349 & $\begin{array}{c}15 \\
(11.0,20.0)\end{array}$ & $\begin{array}{c}13 \\
(8.0,18.0)\end{array}$ & 0.033 \\
\hline
\end{tabular}

The scores of Greene's climacteric scale in pre-, peri- and postmenopausal nurses are presented as medians with $25^{\text {th }}$ and $75^{\text {th }}$ percentiles.

Table 4. Job-related stress factors in nurses in Smokers and Non-smokers.

\begin{tabular}{cccc}
\hline & $\begin{array}{c}\text { smokers } \\
(\mathbf{n}=122)\end{array}$ & $\begin{array}{c}\text { non-smokers } \\
(\mathbf{n}=1057)\end{array}$ & p value \\
\hline Quantitative overload & $5.4(1.8)$ & $5.3(1.8)$ & 0.691 \\
Qualitative overload & $5.0(1.7)$ & $4.9(1.6)$ & 0.519 \\
Physical overload & $2.0(0.8)$ & $1.9(0.8)$ & 0.731 \\
Job control & $7.3(1.8)$ & $7.4(1.8)$ & 0.806 \\
Skill discretion & $3.2(0.7)$ & $3.1(0.7)$ & 0.307 \\
Interpersonal relationship & $8.6(1.8)$ & $8.7(1.7)$ & 0.792 \\
Workplace environment & $2.8(0.9)$ & $2.9(0.9)$ & 0.293 \\
Job fitness & $2.8(0.7)$ & $2.8(0.7)$ & 0.585 \\
Job satisfaction & $3.1(0.8)$ & $3.1(0.7)$ & 0.826 \\
Total & $40.1(5.9)$ & $40.2(5.6)$ & 0.973 \\
\hline
\end{tabular}

Mean (SD).

score for the stress factor of interpersonal relationships was significantly higher in smokers $(9.2 \pm 1.5$ points $)$ than in non-smokers $(8.5 \pm 1.7$ points $)(p=0.024)$ (data not shown). 


\section{Discussion}

In the present study, we found that the proportion of smokers in postmenopausal nurses is significantly higher than that in premenopausal nurses and that nurses with a current smoking habit are more likely than non-smokers to have quick or strong heart beating, difficulty in sleeping, loss of interest in most things, and night sweating.

It has been reported that the proportion of smokers in peri- and postmenopausal women was significantly larger than that in premenopausal women [16]. Our results are in agreement with the results of that study. Also, it has been reported that past smoking and current smoking were related to prevalence of heart pounding and difficulty in sleeping [5] and that smokers had more difficulty in sleeping than did non-smokers in Japanese women [10]. Regarding vasomotor symptoms, some studies have shown that there was a relationship between smoking and hot flashes. It has been reported that daily smoking was significantly associated with the intensity of hot flashes [6]. The results of a meta-analysis showed that former smoking and current smoking are associated with an increased risk of hot flashes [7]. We found that current smokers were likely to have night sweats but not hot flashes. A previous study showed that past smoking and current smoking was related to a high prevalence of hot flashes or night sweats [5]. It was shown in another study that current smokers were significantly more likely to report night sweats than were subjects who had never smoked [17]. The reason for the higher prevalence of night sweats than that of hot flashes is not clear.

In the present study, no significant difference in the clusters of menopausal symptoms, except for the anxiety sub-cluster, was found between smokers and non-smokers. The results are consistent with the results of a previous study showing that smoking status was not related to menopausal psychological, somatic and vasomotor symptoms [16]. However, focusing on menopausal status, the scores for total menopausal symptoms and for the vasomotor cluster and anxiety sub-cluster in smokers were higher than those in non-smokers only in postmenopause. We also found that certain menopausal symptoms appeared to be more severe in smokers than in non-smokers and that some symptoms were more severe in postmenopause.

There have been many studies showing that smoking is associated with earlier menopause [6] [18] [19]. In our study, the proportion of smokers who had experienced menopausal symptoms was higher than the proportion of non-smokers, and the age that smokers started to have symptoms was 1 year younger than the age in non-smokers, but the difference was not significant. It was shown in a previous study that current smokers had a slightly increased risk of onset of menopausal symptoms compared to individuals who had never smoked [20]. The results of previous studies and our study suggest that menopausal symptoms tend to occur earlier in smokers than in non-smokers. Considering the results of previous studies regarding smoking and earlier start of menopause, 
women should be encouraged to quit smoking as soon as possible before menopausal transition.

We showed that only the score for the stress factors of interpersonal relationships in perimenopause was significantly higher in smokers than in non-smokers. It has been reported that there was no significant relationship between any of the major occupational stress factors (burden of work, control of work, personal relationships, and adaptability to work) and smoking habit in nurses [21] [22] and that the score for stressors and stress reactions in nurses with a smoking habit was higher than that in nurses without a smoking habit [23]. In addition, in hospital nurses, conflict in a ward was showed to be positively associated with smoking among nurses, while good human relations between other nurses in the ward was shown to be negatively associated with smoking [24]. Our results may indicate that human relationships in the work place are risk factors for smoking habits among nurses. It has been shown that nurses tended to smoke when they were feeling irritated, drinking alcohol and doing something for a changing in feelings [25]. Smoking might be one of the means for stress management in nurses who feel stressful during menopausal transition.

It has been reported that the proportion of the subjects who had vasomotor symptoms such as hot flashes and sweating in women with metabolic syndrome was higher than that in women without metabolic syndrome [26]. Women who report having hot flashes or night sweats "often" have an increased risk of developing coronary heart disease over a period of 14 years [27]. Women who have more severe menopausal symptoms may have a risk of lifestyle-related disease. The associations of smoking with cardiovascular diseases are well known. Promotion of a healthy life style include smoking cessation is needed for women before the menopausal transition. We found that there was a relationship between smoking and menopausal symptoms. Strict tobacco control measures for the smokers are needed to prevent aggravation of menopausal symptoms.

There are several limitations in the study. First, the causal relationship between smoking and menopausal symptoms has not been clarified since this study had a cross-sectional nature. Second, there was a disproportion in the ratios of premenopausal women, perimenopausal women and postmenopausal women. This might be influenced to our result. Third, we did not ask questions about smoking status, age of starting smoking, smoking quantity, age of smoking cessation and changes in smoking after menopausal symptoms started. Fourth, information on nurse license and working department was lacking. In addition, the level of the nurse, working shift, and job stress may be a compounding factor. Further study should be involved to analyze these potential factors to influence the menopausal symptoms and smoking.

\section{Conclusion}

In Japanese female nurses, smokers are more likely than non-smokers to have menopausal symptoms such as heart beating quickly or strongly, difficulty in 
sleeping, loss of interested in most things and sweating at night. Support to stop smoking should be provided before menopausal transition in order to prevent deterioration of menopausal symptoms and to prevent health problems in the future.

\section{Acknowledgements}

The authors extend their thanks to the participants in this study.

\section{Conflicts of Interest}

The authors declare no conflicts of interest regarding the publication of this paper.

\section{References}

[1] Japanese Society of Obstetrics and Gynecology (2018) Sankafujinkayougosyuu/ Yougokaisetusyuu [Glossary of Obstetrics and Gynecology]. 4th Edition, Japanese Society of Obstetrics and Gynecology, Tokyo. (In Japanese)

[2] Lock, M. (2000) Culture and the menopause. In: Aso, T., Yanaihara, T. and Fujimoto, S., Eds., The Menopause at the Millennium: The Proceedings of the 9 th International Menopause Society World Congress on the Menopause, The Parthenon Publishing Group, New York \& Lancs, 29-35.

[3] Liu, M., Wang, Y., Li, X., Liu, P., Yao, C., Ding, Y., Zhu, S., Bai, W. and Liu, J.E. (2013) A Health Survey of Beijing Middle-Aged Registered Nurses during Menopause. Maturitas, 74, 84-88. https://doi.org/10.1016/j.maturitas.2012.10.006

[4] Matsuzaki, K., Uemura, H. and Yasui, T. (2014) Associations of Menopausal Symptoms with Job-Related Stress Factors in Nurses in Japan. Maturitas, 79, 77-85. https://doi.org/10.1016/j.maturitas.2014.06.007

[5] Gold, E.B., Sternfeld, B., Kelsey, J.L., Brown, C., Mouton, C., Reame, N., Salamone L. and Stellato, R. (2000) Relation of Demographic and Lifestyle Factors to Symptoms in Multi-Racial/Ethnic Population of Women 40-55 Years of Age. American Journal of Epidemiology, 152, 463-473. https://doi.org/10.1093/aje/152.5.463

[6] Gjelsvik, B., Rosvold, E.O., Straand, J., Dalen, I. and Hunskaar, S. (2011) Symptom Prevalence during Menopause and Factors Associated with Symptoms and Menopausal Age. Results from the Norwegian Hordaland Women's Cohort Study. Maturitas, 70, 383-390. https://doi.org/10.1016/j.maturitas.2011.09.011

[7] Jenabi, E. and Poorolajal, P. (2015) The Association between Hot Flushes and Smoking in Midlife Women: A Meta-Analysis. Climacteric, 18, 797-801. https://doi.org/10.3109/13697137.2015.1080236

[8] Pérez, J.A.M., Garcia, F.C., Palacios, S. and Pérez, M. (2009) Epidemiology of Risk Factors and Symptoms Associated with Menopause in Spanish Women. Maturitas, 62, 30-36. https://doi.org/10.1016/j.maturitas.2008.10.003

[9] Capistrano, E.J.M., Dombek, K., Costa, A.C.C. and Marinheiro, L.P.F. (2015) Factors Associated with the Severity of Menopausal Symptoms in Postmenopausal Brazilian Women. Reprodução \& Climatério, 30, 70-76.

https://doi.org/10.1016/j.recli.2015.09.002

[10] Oi, N. and Ohi, K. (2012) A Study of Menopausal Symptoms in Relation to Habits of Smoking and Make-Up Using in Japanese Women Aged 35-59. International Journal of Cosmetic Science, 34, 332-337. 
https://doi.org/10.1111/j.1468-2494.2012.00722.x

[11] Lee, J.S., Hayashi, K., Mishra, G., Yasui, T., Kubota, T. and Mizunuma, H. (2013) Independent Association between Age at Natural Menopause and Hypercholesterolemia, Hypertension, and Diabetes Mellitus: Japan Nurses' Health Study. Journal of Atherosclerosis and Thrombosis, 20, 161-169. https://doi.org/10.5551/jat.14746

[12] Miyazaki, Y., Hayashi, K., Mizunuma, H., Lee, J.S., Katanoda, K., Imazeki, S. and Suzuki, S. (2013) Smoking Habits in Relation to Reproductive Events among Japanese Women: Findings of the Japanese Nurses' Health Study. Preventive Medicine, 57, 729-731. https://doi.org/10.1016/j.ypmed.2013.08.004

[13] Yasui, T., Hayashi, K., Mizunuma, H., Kubota, T., Aso, T., Matsumura, Y., Lee, J.S. and Suzuki, S. (2012) Factors Associated with Premature Ovarian Failure, Early Menopause and Earlier Onset of Menopause in Japanese Women. Maturitas, 72, 249-255. https://doi.org/10.1016/j.maturitas.2012.04.002

[14] Greene, J.G. (1998) Constructing a Standard Climacteric Scale. Maturitas, 29, 25-31. https://doi.org/10.1016/S0378-5122(98)00025-5

[15] Shimomitsu, T., Yokoyama, K., Ohno, H., Maruta, T. and Tanigawa, T. (2000) Manual of the Brief Job Stress Questionnaire. In: Reports on the Study of Job Stress and Its Effects on health in the Workplace: The Research Grant for the Prevention of Work-Related Diseases from the Japan Ministry of Labour, The Ministry of Labour, Tokyo, 17-27. (In Japanese)

[16] Moilanen, J., Aalto, A.-M., Hemminki, E., Aro, A.R., Raitanen, J. and Luoto, R. (2010) Prevalence of Menopause Symptoms and Their Association with Lifestyle among Finnish Middle-Aged Women. Maturitas, 67, 368-374.

https://doi.org/10.1016/j.maturitas.2010.08.007

[17] Duffy, O.K., Iversen, L. and Hannaford, P.C. (2013) Factors Associated with Reporting Classic Menopausal Symptoms Differ. Climacteric, 16, 240-251. https://doi.org/10.3109/13697137.2012.697227

[18] Schoenaker, D.A., Jackson, C.A., Rowlands, J.V. and Mishra, G.D. (2014) Socioeconomic Position, Lifestyle Factors and Age at Natural Menopause: A Systematic Review and Meta-Analyses of Studies across Six Continents. International Journal of Epidemiology, 43, 1542-1562. https://doi.org/10.1093/ije/dyu094

[19] Yang, H.J, Suh, P.S., Kim, S.J. and Lee, S.Y. (2015) Effects of Smoking on Menopausal Age: Results from the Korea National Health and Nutrition Examination Survey, 2007 to 2012. Journal of Preventive Medicine \& Public Health, 48, 216-224. https://doi.org/10.3961/jpmph.15.021

[20] Sabia, S., Fournier, A., Mesrine, S., Boutron-Ruault, M.C. and Clavel-Chapelon, F. (2008) Risk Factors for Onset of Menopausal Symptoms: Results from a Large Cohort Study. Maturitas, 60, 108-121. https://doi.org/10.1016/j.maturitas.2008.04.004

[21] Ota, A., Yasuda, N., Okamoto, Y., Kobayashi, Y., Sugihara, Y., Koda, S., Kawakami, N. and Ohara, H. (2004) Relationship of Job Stress with Nicotine Dependence of Smokers-A Cross-Sectional Study of Female Nurses in a General Hospital. Journal of Occupational Health, 46, 220-224. https://doi.org/10.1539/joh.46.220

[22] Tsukahara, H., Sakaguchi, C., Mitsuno, Y., Takagi, A., Katou, T., Asada, A. and Matsunaga, K. (2007) The Association between Smoking and Stress among Nurses. Medical Bulletin of Fukuoka University, 34, 285-290. (In Japanese)

[23] Yamano, Y., Terada, E. and Yamada, F. (2014) The Relationship between Smoking Behavior and Stress in Nurses. Kinen Kagaku, 8, 1-8. (In Japanese)

[24] Imamura, T., Washio, M., Yamada, K., Shibata, K., Toyomasu, K. and Ide, S. (2009) Factors Related to Smoking Habits Among Female Nurses in a General Hospital. 
Japanese Journal of Cardiovascular Disease Prevention, 44, 161-168. (In Japanese)

[25] Japanese Nursing Association (2007) Report of the Survey on Smoking among Nurses in 2006. (In Japanese)

https://www.nurse.or.jp/home/publication/pdf/tabaco/kango tabacojittai 2006.pdf

[26] Lee, S.W., Jo, H.H., Kim, M.R., Kwon, D.J., You, Y.O. and Kim, J.H. (2012) Association between Menopausal Symptoms and Metabolic Syndrome in Postmenopausal Women. Archives of Gynecology and Obstetrics, 285, 541-548. https://doi.org/10.1007/s00404-011-2016-5

[27] Herber-Gast, G., Brown, W.J. and Mishra, G.D. (2015) Hot Flushes and Night Sweats Are Associated with Coronary Heart Disease Risk in Midlife: A Longitudinal Study. BJOG, 122, 1560-1567. https://doi.org/10.1111/1471-0528.13163 